\title{
Microbending in photonic crystal fibres - an ultimate loss limit?
}

Bjarklev, Anders Overgaard; Hansen, Theis Peter; Hougaard, Kristian G.; Libori, S.E. Barkou; Knudsen, Erik; Broeng, Jes

Published in:

27th European Conference on Optical Communication, 2001. ECOC '01.

Link to article, DOI:

10.1109/ECOC.2001.989648

Publication date:

2001

Document Version

Publisher's PDF, also known as Version of record

Link back to DTU Orbit

Citation (APA):

Bjarklev, A. O., Hansen, T. P., Hougaard, K. G., Libori, S. E. B., Knudsen, E., \& Broeng, J. (2001). Microbending in photonic crystal fibres - an ultimate loss limit? In 27th European Conference on Optical Communication, 2001. ECOC '01. (Vol. 3). IEEE. https://doi.org/10.1109/ECOC.2001.989648

\section{General rights}

Copyright and moral rights for the publications made accessible in the public portal are retained by the authors and/or other copyright owners and it is a condition of accessing publications that users recognise and abide by the legal requirements associated with these rights.

- Users may download and print one copy of any publication from the public portal for the purpose of private study or research.

- You may not further distribute the material or use it for any profit-making activity or commercial gain

- You may freely distribute the URL identifying the publication in the public portal 


\title{
Microbending in photonic crystal fibres - An ultimate loss limit?
}

\author{
Anders Bjarklev, Theis P. Hansen, Kristian Hougaard, Stig Barkou Libori, Erik \\ Knudsen, and Jes Broeng
}

COM, Technical University of Denmark, DTU Building 345v, DK-2800 Kgs.Lyngby, Denmark, Tel. +4545253809, Fax: + 4545936581 (ab@com.dtu.dk)

Abstract: Microbending losses are for the first time estimated in index-guiding photonic crystal fibres, and comparisons with standard step-index fibres are made. The results indicate that typical photonic crystal fibres are significantly less sensitive (one order of magnitude smaller loss) towards microbending than standard optical fibres.

\section{Introduction}

The research area of Photonic Crystal Fibres (PCFs) has since its appearance about five years ago $[1,2]$ received a significant interest from the scientific community. One of the primary reasons for this interst is that these periodically microstructured optical fibres with a high-index contrast (they typically consists of air holes in a silica background material) provide properties that are unattainable by standard fibre technology. Among these new fibres are highly non-linear PCFs, which may be used for continuum generation [3], or large-mode-area (LMA) PCFs with high bending loss resistance [4]. The photonic crystal fibres may conveniently be divided into two very different groups. The first is fibres having a high-index core (typically solid silica) surrounded by a two-dimensional photonic-crystal cladding-structure. These fibres guide by a Total Internal Reflection (TIR) like principle [5]. Radically different to these TIR-PCFs are fibres, where the photonic-crystalcladding structure is exhibiting the photonic bandgap (PBG) effect, and where this effect is utilised to confine light in the core region [6]. Since the research on PCFs still represents a relatively young field, numerus questions concerning the fundamental properties and potential applications need to be answered. Among the central issues are naturally, what the fundamental loss limits for these microstructured fibres are - and whether or not they have a potential as transmission fibres for future optical communication systems. Concerning the transmission loss limits, it is noteworthy that PCFs may be fabricated by undoped (and very pure) silica glass - pointing towards potentially very low losses, but other fundamental sources of attenuation have not yet been addressed in much detail. Among the key questions that have not yet been answered is the microbending sensitivity of PCFs, which due to the high index contrast between air holes and silica may be expected to be significant in PCFs compared to standard optical fibres. In this paper, we will for the first time address this issue of microbending in PCFs.

\section{Microbending loss description}

It is well known from standard fibre theory that deformations along the longitudinal direction of a singlemode fibre will cause power to be lost from the fundamental mode. This loss mechanism may generally be described by application of the perturbation theory [7,8] describing coupling between the guided mode and the cladding modes of a distorted single-mode fibre.

The microbending power loss formula based on the coupled mode theory $[7,8]$ may be expressed as

$$
2 \alpha=\sum^{\infty} C_{1 p}^{2} \cdot \Phi\left(\Delta \beta_{1 p}\right)
$$

In this expression $\mathrm{C}_{1 \mathrm{p}}$ is the position independent coupling coefficient, which describes the coupling strength between the fundamental mode (the $L P_{01}$ mode in standard optical fibres) and the cladding mode (the $L P_{1 p}$ mode). The formula shows furthermore that the size of each loss contribution $\Phi$ depends on the value of the deformation spectrum $\Delta \beta_{1}$ at the spatial frequency, which is the difference between the propagation constant of the guided mode and the actual cladding mode indicated by the parameter $p$. In the case of microbends, the coupling coefficients may be written as $[7,9]$

$$
C_{1 p}^{2}=\frac{k^{2}}{2} \frac{\left(\int_{0}^{\infty} n_{b} E_{01} E_{p}^{1} r d r\right)^{2}}{\int_{0}^{\infty} E_{01}^{2} r d r \int_{0}^{\infty}\left(E_{p}^{1}\right)^{2} r d r}
$$

where $k=2 \pi / \lambda$ is the free space wavenumber. The electrical fields $E_{01}$ corresponds to the fundamental mode, and $E_{1}{ }^{p}$ is the electrical field of cladding mode $p$. The parameter $r$ is the radial integration parameter and $n_{b}$ is the index perturbation. In a step along the length of the fibre, the index perturbation may be seen as a small lateral movement one of two adjacent segments, which means that the only significant contribution to the integrals are to be found where the original index profile varies in lateral position. In the case of a PCF this corresponds to integrations around the air holes as indicated in Fig.1, and in a step-index fibre (SIF) the core cladding interface will contribute to the coupling loss integral.

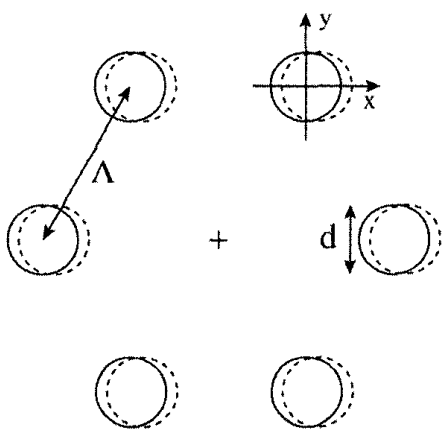

Figure 1: Perturbation of PCF index profile due to lateral microdeformation in the $x$-direction. Also indicated are the pitch $\Lambda$ and the air-hole diameter $d$. 
To descibe the mode fields in PCFs (and for comparison in standard SIFs), the mode fields have been calculated using a full vectorial mode solver. The cladding modes have been determined by a super-cell representation of the fibre structure, in which the outer fibre diameters have been truncated as indicated in Fig.2. This figure also illustrates examples of the mode fields guided by the core of a highindex PCF and one of the cladding mode fields.

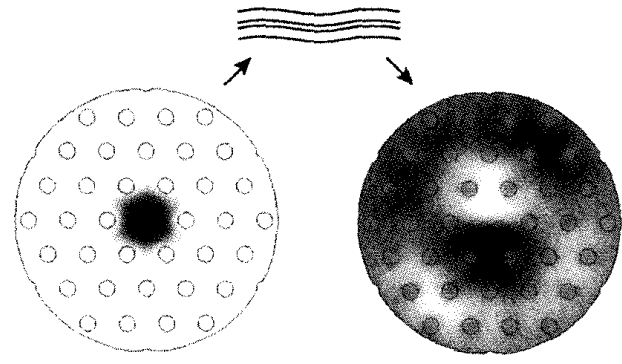

Figure 2: Fundamental mode (left) and cladding mode (corresponding to $\mathrm{LP}_{11}$ mode of standard optical fibres) in truncated PFC fibre cross sections.

\section{Comparison of microbending loss in SIF and PCF}

In order to evaluate the microdeformation loss in PCFs in an accurate manner, it will be necessary to perform several experiments concerning relations between surface deformations and core deformations, and a more complicated theory must be used compared to that of standard optical fibres $/ 10 /$. Since it, however, at this point merely is the goal to make a first and relatively simple evaluation, it has been assumed that both SIF and PCF are exposed to the same deformation spectrum given by $\Phi(\Omega)=\mathrm{A} / \Omega^{8}[11]$.

The selected fibres for the comparison are given as follows: The SIF index profile is given by a radius of $2.25 \mu \mathrm{m}$, and a core-cladding refractive index difference of $\Delta n=0.008$. The outer radius of the SIF is $10 \mu \mathrm{m}$, the refractive index of the core is 1.45 , and the refractive index of the material surrounding the fibres is 1.0. For the PCF, the pitch is $\Lambda=3 \mu \mathrm{m}$ and the relative air hole diameter is $\mathrm{d} / \Lambda=0.4$. Furthermore, the PCF is described by a refractive index of silica of 1.45 , and the outer truncation is at a radial value of $10 \mu \mathrm{m}$ from the fibre centre. In both situations, super-cells are chosen with dimensions so that two (virtual) neighbouring fibres are spaced by $1 \mu \mathrm{m}$.

Fig. 3 illustrates the key results of our investigation. Each of the bars shown in Fig. 3 indicate the relative magnitude of the coupling coefficient between the fundamental mode and each of the higher-order modes (or cladding modes) calculated for the SIF or the PCF structures, respectively. It should be noted that coupling coefficients due to perturbations as indicated in Fig.1, give no practical coupling to even higher-order modes (of a type similar to those of $L P_{0}$ modes). Fig.3, however, shows the expected bars due to coupling to modes corresponding to $L P_{1 p}$ modes, and we note that the coupling coefficients are placed in groups (with small $\Delta \beta$-distance), corresponding to different (non-degenerate) eigenvalues of modes of similar shape/type.

Comparing the coupling coefficients for the SIF and the PCF, we note that the SIF has significantly lower spatial frequency spacing between the guided and the lowest order cladding modes. This results in a much stronger loss contribution in the SIF due to the strongly decreasing function describing the deformation spectrum. On the other hand, the very large refractive index gradient in silica-hole interface present in the PCF leads to higher coupling coefficients compared to similar mode spacing in the SIF. Typical differences in coupling coefficient magnitudes of a factor of 5 are seen in Fig.3. However, when weighted by the deformation spectrum, the microbending loss in the PCF is about one order of magnitude smaller than in the standard SIF.

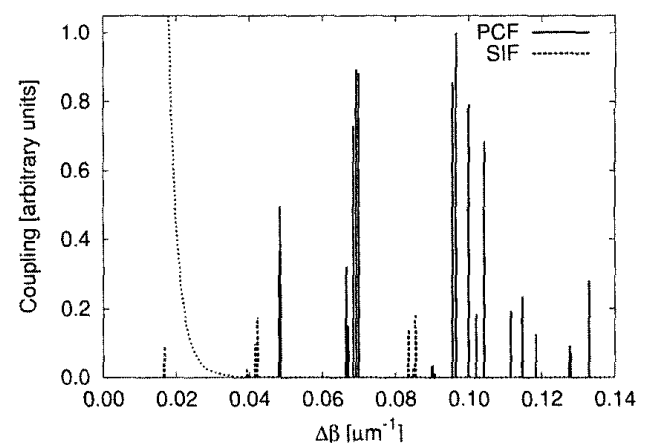

Figure 3: Coupling coefficients of standard step-index fibre (dotted bars) and of index guiding photonic crystal fibre (solid bars). Also shown is the shape of the deformation spectrum used for comparison of loss levels. Calculations are made at a wavelength of $1550 \mathrm{~nm}$.

\section{Summary}

We may as a guidline assume that typical microbending losses in standard optical fibres (i.e., induced through cabling) are about $0.1 \mathrm{~dB} / \mathrm{km}$. These first comparisons between microbending losses in standard fibres and photonic crystal fibres indicate that we may expect microbending losses in the order of $0.01 \mathrm{~dB} / \mathrm{km}$ for a typical PCF design - primarily due to a stronger mode spacing between guided modes and cladding modes in PCFs. Although this conclusion naturally may vary strongly due to the far reaching possibilities for design variations allowed by the PCF technology, we believe that the results are very promising for the possible future applications of photonic crystal fibres. Further results on microbending sensitivity of PCFs will be presented.

\section{References}

11 T.A.Birks et al., IEE Electr. Lett., 31 (1995), pp. 1941-1943.

12/ J.C.Knight et al., OFC'96, 2, Paper CH35901 (1996).

13/ J.K.Ranka et al., Optics Lett., 25 (2000), pp.25-27.

14/ T.Sørensen et al., IEE Electr. Lett., 37 (2001), pp. 287-289.

15/ J.C. Knight et al., Optics Lett., 21 (1996), pp.15471549.

16/ J.C. Knight et al., Science, 282 (1998), pp. 1476-1478.

17 D.Markuse, New York: Academic, 1974.

18/ H.G.unger, Oxford, England: Clarendon, 1977.

19/ D.Marcuse, Appl.Opt., 23 (1984), pp.1082-1091.

/10/ C.B.probst et al., IEEE JLT, 7 (1989), pp.55-61.

111/ S.Hornung et al., Opt. And Quant. Electr., 14 (1982), pp.359-362. 